\title{
IL-4 and IL-5 Secretions Predominate in the Airways of Wistar Rats Exposed to Toluene Diisocyanate Vapor
}

\author{
Kouame Kouadio ${ }^{1,2}$, Kui-Cheng Zheng ${ }^{1,3}$, Abdoulaye Abba Toure' ${ }^{2}$, Mireille Dosso ${ }^{2}$, Hidemi Todoriki ${ }^{1}$ \\ ${ }^{1}$ Department of Environmental and Preventive Medicine, Faculty of Medicine, University of the Ryukyus, Okinawa, Japan; ${ }^{2}$ Eco-epidemiology Unit, \\ Department of Environmental Health, Institut Pasteur of Côte d'Ivoire, Côte d'Ivoire, West Africa; ${ }^{3}$ Fujian Provincial Center for Desease Control, Fu- \\ zhou, China
}

Objectives: We established a Wistar rat model of asthma caused by toluene diisocyanate (TDI) exposure, and investigated the relationship between TDI exposure concentrations and respiratory hypersensitivity, airway inflammation, and cytokine secretions in animals, to better understand the mechanism of TDI induced occupational asthma.

Methods: Wistar rats were exposed to two different concentrations of TDI vapor four hours a day for five consecutive days. Bronchoalveolar lavage (BAL) was performed, and differential leucocytes from the BAL fluid were analyzed. Lung histopathological examination was carried out to investigate the inflammatory status in the airways. Production of cytokines interleukin (IL)-4 and IL-5 productions in the BAL fluid in vivo was determined with enzyme-linked immunosorbent assay kits.

Results: The TDI-exposed rats exhibited greater airway hypersensitivity symptoms than the control rats. The BAL differential cell count and lung histopathological examination demonstrated that inflammation reactions were present in both the central and peripheral airways, characterized with marked infiltration of eosinophils in the TDI-exposed rats. The cytokine assay showed that IL-4 and IL-5 were predominantly produced in the BAL fluid in vivo.

Conclusions: These findings imply that TDI exposure concentrations may greatly affect the occurrence and extent of inflammatory events and that Th2 type cytokines may play an important role in the immunopathogenesis of TDI-induced occupational respiratory hypersensitivity.

Key words: Toluene 2,4-diisocyanate, Wistar rat, Bronchoalveolar lavage, Cytokines, Eosinophils, Airway

\section{INTRODUCTION}

Asthma is a chronic respiratory disease characterized by the presence of reversible airway constriction and airway hyperresponsiveness to various stimuli. Nearly nine million individuals

Received: August 17, 2013; Accepted: December 4, 2013

Corresponding author: Kouame Kouadio, MD, PhD

01 BP 490 Abidjan 01, Côte d'Ivoire, West Africa

Tel: +225-06-29-44-20, Fax: +225-22-48-53-05

E-mail: kouadiokouame@yahoo.com

This is an Open Access article distributed under the terms of the Creative Commons Attribution Non-Commercial License (http://creativecommons.org/licenses/bync/3.0// which permits unrestricted non-commercial use, distribution, and reproduction in any medium, provided the original work is properly cited. are exposed to agents at their workplace associated with asth$\mathrm{ma}$, and isocyanates such as toluene diisocyanate (TDI) are the most common cause of occupational asthma [1]. TDI induced asthma has been difficult to diagnose and control, in part because the biological mechanisms responsible for the disease and the determinants of exposure have not yet been defined and validated animal models do not yet exist [2-4]. Studies in humans and animals have been conducted in many laboratories to define the underlying mechanism of occupational asthma. Results have shown that the bronchial inflammation characteristic of asthma represents a type of cell-mediated immunity in which a specialized population of activated lymphocytes interacts with other inflammatory cells through an array of chemical mediators including cytokines. In an experiment by 
Zheng and Ariizumi [5], a mouse asthmatic model exposed to $1.35 \pm 0.27 \mathrm{ppm}$ TDI vapor, 4 hours a day for 5 consecutive days, showed that cytokine interleukin (IL)-4 and IL-5 were significantly increased in the airways of the animals, implying their important role in TDI-induced pulmonary hypersensitivity. In order to better understand how the immunopathogenicity of TDI induces occupational asthma, a Wistar rat model of asthma has been developed. Rats were exposed to two different concentrations of TDI vapor since workers are exposed mainly to TDI vapor at their workplaces. In the studies of Kouadio et al. [6], Wistar rats were also exposed to two different concentrations of TDI vapor. However, IL-5 secretion was not measured due to the lack of an available testing kit. In order to understand the key role that IL-4 and IL-5 cytokines may play in this model, Wistar rats were exposed to TDI vapor under the same conditions, and the cytokines produced were determined with enzyme-linked immunosorbent assay (ELISA) kits to better understand the role that cytokines may play in the occurrence of asthma and especially occupational asthma.

\section{METHODS}

\section{Rats}

Fifteen 8-week-old female Wistar rats, weighing $243 \pm 30 \mathrm{~g}$, were obtained from Kyudo Breeding Laboratories (Kumamoto, Japan). Upon arrival, the rats were quarantined in a room at a constant temperature $\left(25 \pm 2^{\circ} \mathrm{C}\right.$ ) and humidity (50 to $70 \%$ ). The animals were housed in cages in pathogen-free and environmentally controlled conditions in compliance with the Ryukyu University policy on animal care and use. Food and water were provided ad libitum throughout the experimental period except during periods of short inhalation exposure. The animals were allowed to acclimatize to our laboratory for one week, and then 5 rats were randomly selected for the control group. The remaining 10 rats were randomly divided into two groups of 5 rats each (groups 1 and 2) and exposed to different concentrations of TDI vapor. This animal experiment was handled according to the regulations of Japanese law related to the use of animals for research.

\section{Quantification of Toluene Diisocyanate Concen- trations and Sensitization Procedures}

A 22L Plexiglas inhalation chamber was used for this study. The rats in groups 1 and 2 were exposed to 2, 4 TDI (Wako Chemical Co., Osaka, Japan) vapor, 4 hours per day for 5 con- secutive days. The TDI atmospheres were obtained by bubbling air through an impinger containing 2,4 TDI into the chamber containing the rats. By varying the airflow rate through the impinger or through the exposure chamber, the TDI concentrations were obtained. Analytical determinations of TDI atmospheres in the chamber were conducted according to Marcali [7], as modified by National Institute for Occupational Safety and Health [8] and reported by other studies [3,9-12]. Briefly, the air in the chamber was sampled with an impinger containing an absorber medium made from acetic and hydrochloric acids. Several solutions, diazotization solution containing sodium nitrite and sodium bromide, sulfamic acid solution, $\mathrm{N}$-1-napthylethylenediamine and sodium carbonate solution, were then added to the absorber medium. When a reddish-blue solution was finally formed, its transmittance was measured at $550 \mathrm{~nm}$ with a spectrophotometer. The TDI concentration was evaluated from a calibration curve of a series of standard TDI solutions prepared by plotting transmittance versus TDI standard concentrations. The TDI concentration was expressed as a mean \pm standard deviation (SD) and adjusted to $0.41 \pm 0.05 \mathrm{ppm}$ and $1.14 \pm 0.11 \mathrm{ppm}$ for exposure groups 1 and 2 . The control group was placed in the same chamber and treated under the same conditions except that the flask contained air instead of TDI. The animals were challenged with $0.005 \mathrm{ppm}$ of TDI.

\section{Bronchoalveolar Lavage}

Immediately after a 5-day exposure to TDI vapors or air, the rats in both the exposure and control groups were anesthetized by intraperitoneal injection with $50 \mathrm{mg} / \mathrm{kg}$ of sodium pentobarbital. A cervical incision was made and the trachea was isolated. A catheter was then inserted into the trachea and bronchoalveolar lavage (BAL) was performed. The trachea was infused with $1.5 \mathrm{~mL}$ of phosphate buffered saline $\left(37^{\circ} \mathrm{C}\right)$ and the effluent collected after the lungs were washed was gently recovered and centrifuged at $500 \mathrm{~g}\left(4^{\circ} \mathrm{C}\right)$. The BAL fluid (BALF) was collected and stored at $-80^{\circ} \mathrm{C}$ until the cytokines were quantified.

\section{Cytokine Assay}

IL-4 and IL-5 production in BALF was quantified with rat IL-4 and IL-5 ELISA kits (Endogen Inc., Woburn, MA, USA), respectively, according to the protocols recommended by the manufacturer. The inter-assay and intra-assay coefficients of variation, were $<10 \%$. The sensitivities of the assays were $<2 \mathrm{pg} / \mathrm{mL}$ and $<5 \mathrm{pg} / \mathrm{mL}$ for IL-4 and IL-5, respectively. 


\section{Histopathological Study}

Immediately after collecting BALF, $1 \mathrm{~mL}$ of formaldehyde was injected into the trachea. The lungs were resected and fixed in buffered formalin. A section encompassing the maximum crosssectional area of the right lung was taken perpendicular to the major bronchi, dehydrated through a series of ethanol solutions, and then embedded in paraffin. Two-micrometer-thick sections were sliced and stained with hematoxylin-eosin for examination.

\section{Statistical Analysis}

The data on cytokine production were presented as means \pm SD. A two-tailed Mann-Whitney $U$-test was applied to reveal differences between the exposure groups and control groups. A value of $p<0.05$ was considered statistically significant.

\section{RESULTS}

\section{Hypersensitivity Symptoms in Airway}

As shown in Table 1, TDI exposure resulted in airway hypersensitivity in the rats. These symptoms generally appeared from the 4th day. The rats in exposure group 1 (0.41 ppm) exhibited mild sneezing from the 2nd day. These symptoms became moderate on the 5th day. Mild hyperrhinorrhea and in-

Table 1. Hypersensitivity symptoms in the airways of wistar rats

\begin{tabular}{lcccccc}
\hline & \multicolumn{5}{c}{ Hypersensitivity symptoms } \\
\cline { 2 - 6 } Treatment & Sneeze & $\begin{array}{c}\text { Hyperrhi- } \\
\text { norrhea }\end{array}$ & Cough & $\begin{array}{c}\text { Exertional } \\
\text { breathing }\end{array}$ & $\begin{array}{c}\text { Insta- } \\
\text { bility }\end{array}$ \\
\hline Control group & - & - & - & - & - \\
Exposure group 1 & $(0.41 \pm 0.05$ & ppm TDI) & & & \\
Day 1 & - & - & - & - & - \\
Day 2 & + & - & - & - & - \\
Day 3 & + & - & - & - & - \\
Day 4 & + & + & + & + & + \\
Day 5 & ++ & ++ & ++ & +++ & ++ \\
Exposure group 2 (1.14 & +0.11 & ppm TDI) & & & \\
Day 1 & - & - & - & - & - \\
Day 2 & + & + & + & + & ++ \\
Day 3 & ++ & ++ & ++ & ++ & ++ \\
Day 4 & ++ & ++ & ++ & +++ & ++ \\
Day 5 & +++ & +++ & +++ & +++ & +++ \\
\hline
\end{tabular}

Symbols represent the severity of the symptoms. -, no symptom; +, mild symptoms; ++, moderate symptoms; +++, severe symptoms; ++++, much severe symptoms.

Each group contains 5 rats.

TDI, toluene diisocyanate. stability were observed on the 4th day and became moderate at the 5th day. Moreover, a severe exertional breathing appeared on the 5th day. The rats were coughing on day 4 . In contrast to exposure group 1, those in group 2 exposed to 1.14 ppm sneezed moderately on days 3 and 4. Moderate hyperrhinorrhea, instability and cough were present on the 4th day, becoming severe on the 5 th day. Moderate exertional breathing appeared on the 4th day becoming more severe the following day. The rats in the control group, however, did not show any obvious respiratory symptoms. These results suggested that higher doses of TDI might induce more severe respiratory symptoms in rats.

\section{Cytokines in the Bronchoalveolar Lavage Fluid In Vivo}

The cytokine production in the BALF in vivo was determined by using ELISA tests. As shown in Figure 1, the productions of IL-4 was significantly increased in exposure group 1 over the control group $(p<0.05)$. It was also higher in exposure group 2 $(p<0.001)$. Similarly, IL-5 cytokine secretion was significantly high in exposure group $1(p<0.05)$ and the rats in group $2(p<$ 0.001).

\section{Lung Histopathological Analysis}

As described in our previous study [6], the cellular morphology examination demonstrated that inflammatory events occurred in the lungs of rats exposed to TDI. As shown in Table 2, a prominent infiltration of eosinophils was present not only in the mucosa and submucosa of the central airways, but also in the alveoli pulmonum of the peripheral airways. The eosino-

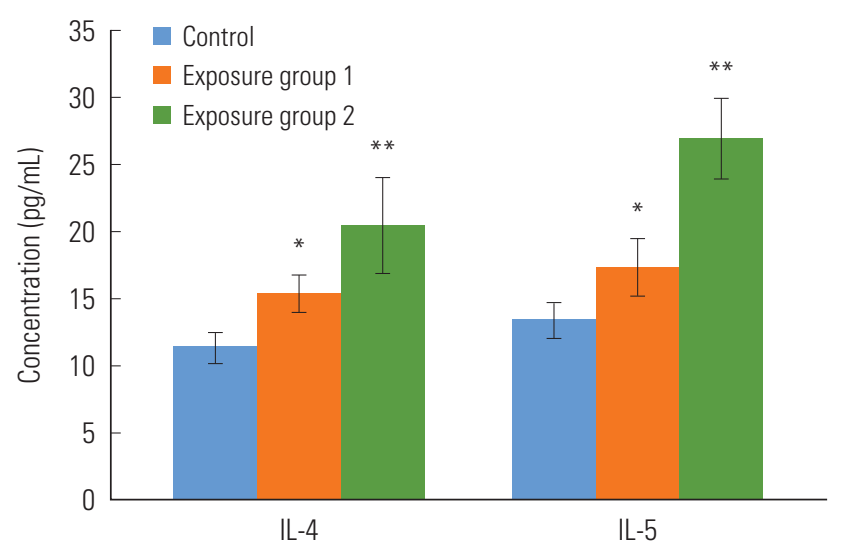

Figure 1. Cytokine production in the bronchoalveolar lavage fluid. Values are means $\pm S D$. Each group contains 5 rats. IL, interleukin. ${ }^{*} p<0.05,{ }^{* *} p<0.01$. 
Table 2. Lungs changes after 5 days exposure to toluene diisocyanate vapor

\begin{tabular}{lccccc}
\hline & \multicolumn{3}{c}{ Central airways } & & $\begin{array}{c}\text { Peripheral } \\
\text { airways }\end{array}$ \\
\cline { 2 - 4 } $\begin{array}{l}\text { Treatment } \\
\text { group }\end{array}$ & \multicolumn{2}{c}{ Mucosal } & & $\begin{array}{c}\text { Submuco- } \\
\text { sal }\end{array}$ & Alveolus \\
\cline { 2 - 3 } & $\begin{array}{c}\text { Goblet cell } \\
\text { metaplasia }\end{array}$ & Eosinophil & Eosinophil & Eosinophil \\
\hline Control & - & - & - & - \\
Exposure 1 & + & ++ & ++ & ++ \\
Exposure 2 & +++ & +++ & +++ & +++ \\
\hline
\end{tabular}

Symbols represent the degree of Wistar rat's lung modification. -, no modification was observed; + , mild modification; ++ , moderate modification; +++ , severe modification.

Each exposure group contains 5 rats.

phil infiltration increased moderately in the central and peripheral airways of exposure group 1 rats. A severe infiltration of eosinophils was present in the alveoli and all the central airways of exposure group 2. Moreover, severe goblet cells metaplasia was present in the epithelium of the central bronchi of exposure group 2. However, moderate goblet metaplasia was present in exposure group 1. In contrast, no major pathological changes were found in the airways of the control rats.

\section{DISCUSSION}

Animal models are typically developed for research and/or testing purposes. For occupational asthma, animal models are particularly needed because of our current incomplete understanding of the mechanisms of chemical sensitization [2]. Many animal models have been developed to understand the mechanisms underlying TDI-induced asthma. Rats have been used for animal asthmatic models $[2,13]$. We established an asthmatic model in this study by exposing Wistar rats in a chamber to two different concentrations of TDI vapor. This sensitization method is more mimetic to the industrial field and has been reported in several other previous studies [3,9-15]. In a guinea pig model exposed to TDI vapor, respiratory hypersensitivity was not detected in animals exposed to $0.12 \mathrm{ppm}$ but was present in animals exposed to $0.36 \mathrm{ppm}$ or greater. Exposure concentrations higher than $2 \mathrm{ppm}$, however, were pneumotoxic and resulted in few pulmonary hypersensitivity reactions [9].

In this study, $0.41 \mathrm{ppm}$, and $1.14 \mathrm{ppm}$ of TDI vapors were used to sensitize Wistar rats. Both concentrations resulted in asthmatic symptoms. However, the symptoms as well as the extent of the respiratory hypersensitivity differed in the two exposed groups. In group 1, exposure to the lowest concentration of $0.41 \mathrm{ppm}$, resulted in irritation and sneezing. In group 2 , exposure to concentrations of $1.14 \mathrm{ppm}$ resulted in more severe asthmatic symptoms characterized by gasping and breathing with an open mouth. The animals were also agitated and hyperactive. These results showed that increasing the concentration of TDI vapor in the chamber enhanced the asthma symptoms in the exposed animals. In a previous guinea pig model, it was found that the respiratory rate decreased in the exposed animals. This decrease was concentration-dependent and exposure to higher TDI concentrations resulted in both a greater percentage of animals producing serum antibodies to TDI and higher antibody titers [9]: moreover, a significant association was found between pulmonary sensitivity and the presence of antibodies to TDI. Although TDI-specific antibodies were not determined in the present study, our results revealed that airway hypersensitivity was concentrationdependent in the TDI-exposed rats.

In this study, the BAL cellular analysis demonstrated that inflammatory cells, in particular, eosinophils, increased along with increasing exposure concentrations. Furthermore, lung histopathological examination confirmed that eosinophil infiltration occurred not only in the central airways but also in the peripheral airways of the exposed animals. Morphological studies in patients with occupational asthma induced by TDI have shown characteristic features of allergic inflammation in the bronchial mucosa, that is infiltration of eosinophils and mast cells [16-21]. Reports have indicated that there is a strong correlation between infiltration of eosinophils and airway inflammation which plays a significant role in the pathogenesis of asthma $[10,18,20-23]$. The results of this study are consistent with studies in humans and other animal studies [5,18,21,22]. Eosinophils are potent proinflammatory cells that release toxic granule proteins such as major basic protein and eosinophil cationic protein: produce of reactive oxygen species, which damage the airway epithelium, promote bronchial hyperresponsiveness, cause mast cell and basophil secretion and directly contract airway smooth muscle $[16,18,20]$. In addition, other eosinophil lipid mediators such as C4, platelet-activating factor and toxic oxygen metabolites are capable of producing broncho-constriction, airway inflammation and hyperresponsiveness [16,20,24].

As immunomodulatory cells participating within cell networks, eosinophils have been recognized to be capable of both responding to cytokines and themselves producing cytokines 


\section{$[19,20,24]$.}

Asthma is recognized as an inflammatory disorder of the airways with respect to pulmonary $T$ cell activation and cytokine production. Studies have shown that asthma is associated with predominant activation of a Th2-like T cell population and cytokines [25-28]. Th1 cells secret IL-2 and their soluble product IFN- $\gamma$, which inhibit the stimulation of IgE antibody responses and the elicitation of immediate type allergic reactions [2527,29-32]. On the other hand, cytokine products of Th2 cells favor the induction of acute allergic responses and immediatetype hypersensitivity $[3,20,32,33]$. IL-4 and IL-5 promote the production of $\lg \mathrm{E}$ antibody and the development, localization and function of eosinophils, respectively $[5,25,29,31,33,34]$. IL-6 acts on a wide range of cellular processes, including $T$ cell activation and immunoglobulin production by $B$ cells, and thus enhances IL-4 dependent IgE synthesis [26-28]. In the airways of patients with allergic asthma, Th2 lymphocytes play a key role in modulating the local inflammatory process that occurs after exposure to an allergen in maintaining bronchial hyperresponsiveness [28]. A mouse model exposed to TDI, showed that IL-4 and IL-10 were preferentially secreted in lymph node cells $[26,27]$, and A guinea pig model exposed to TDI has demonstrated that TNF- $\alpha$ and IL- 6 were increased in BALF [3]. Analysis of the cytokine profile in this study showed a preferential secretion of IL-4 and IL-5 in the exposure groups. These findings are in broad agreement with other previous reports [5,3437] and further supported the concept of the important role of Th2 cytokines in asthma.

In conclusion of this study, IL-5 one of the most important Th2 cytokines, was increased in both exposure group 1 and 2 . Although IL-4 and IL-5 were significantly increased in the rats, in the present study, they were not found to be associated with exposure concentrations or to correlate with respiratory symptoms and BALF cellular content. In order to better understand the role of cytokines in the pathogenesis of occupational asthma induced by TDI exposure, we are currently studying the time course of cytokine secretion under different exposure concentrations and the relationship between cytokines and pulmonary hypersensitivity and infiltration of inflammatory cells.

\section{ACKNOWLEDGEMENTS}

We would like to thank Dr. Takamitsu Morioka, Department of Pathology, Faculty of Medicine, University of the Ryukyus, Okinawa, Japan, for his technical support.

\section{CONFLICT OF INTEREST}

The authors have no conflicts of interest with the material presented in this paper.

\section{REFERENCES}

1. Redlich CA, Karol MH, Graham C, Homer RJ, Holm CT, Wirth $J A$, et al. Airway isocyanate-adducts in asthma induced by exposure to hexamethylene diisocyanate. Scand J Work Environ Health 1997;23(3):227-231.

2. Karol MH, Cormier Y, Donham KJ, Von Essen S, Gruber UF, Lundholm M, et al. Animal models. Am J Ind Med 1994;25(1): 135-138.

3. Ban M, Hettich D, Goutet M, Bonnet P. TDI inhalation in guinea-pigs involves migration of dendritic cells. Toxicol Lett 1997; 93(2-3):185-194.

4. Leigh R, Ellis R, Wattie J, Southam DS, De Hoogh M, Gauldie J, et al. Dysfunction and remodeling of the mouse airway persist after resolution of acute allergen-induced airway inflammation. Am J Respir Cell Mol Biol 2002;27(5):526-535.

5. Zheng KC, Ariizumi M. Interleukin-4 and iterleukin-5 expression in mice exposed to 2-4 toluene diisocyanate. J Occup Health 2002;44:421-426.

6. Kouadio K, Zheng KC, Tuekpe MK, Todoriki H, Ariizumi M. Airway inflammatory and immunological events in a rat model exposed to toluene diisocyanate. Food Chem Toxicol 2005; 43(8):1281-1288.

7. Marcali K. Microdetermination of toluene diisocyanates in atmosphere. Anal Chem 1957;29:552-558.

8. National Institute for Occupational Safety and Health. Occupational exposure to diisocyanates: criteria for a recommended standard. Cincinnati: US Department of Health, Education, and Welfare, Public Health Service, Center for Disease Control, National Institute for Occupational Safety and Health; 1978, p. 78-125.

9. Karol MH. Concentration-dependent immunologic response to toluene diisocyanate (TDI) following inhalation exposure. Toxicol Appl Pharmacol 1983;68(2):229-241.

10. Gordon T, Sheppard D, McDonald DM, Distefano S, Scypinski L. Airway hyperresponsiveness and inflammation induced by toluene diisocyanate in guinea pigs. Am Rev Respir Dis 1985; 132(5):1106-1112.

11. Jin R, Day BW, Karol MH. Toluene diisocyanate protein adducts in the bronchoalveolar lavage of guinea pigs exposed to va- 
pors of the chemical. Chem Res Toxicol 1993;6(6):906-912.

12. Gagnaire F, Ban M, Micillino JC, Lemonnier M, Bonnet P. Bronchial responsiveness and inflammation in guinea-pigs exposed to toluene diisocyanate: a study on single and repeated exposure. Toxicology 1996;114(2):91-100.

13. TyI RW, Neeper-Bradley TL, Fisher LC, Dodd DE, Pritts IM, Losco $P E$, et al. Two-generation reproductive toxicity study of inhaled toluene diisocyanate vapor in CD rats. Toxicol Sci 1999;52(2): 258-268.

14. Karol MH. The development of an animal model for TDI asthma. Bull Eur Physiopathol Respir 1987;23(6):571-576.

15. Kennedy AL, Stock MF, Alarie Y, Brown WE. Uptake and distribution of $14 \mathrm{C}$ during and following inhalation exposure to radioactive toluene diisocyanate. Toxicol Appl Pharmacol 1989; 100(2):280-292.

16. Gleich GJ. The eosinophil and bronchial asthma: current understanding. J Allergy Clin Immunol 1990;85(2):422-436.

17. Paggiaro P, Bacci E, Paoletti P, Bernard P, Dente FL, Marchetti G, et al. Bronchoalveolar lavage and morphology of the airways after cessation of exposure in asthmatic subjects sensitized to toluene diisocyanate. Chest 1990;98(3):536-542.

18. Djukanović R, Wilson JW, Britten KM, Wilson SJ, Walls AF, Roche WR, et al. Quantitation of mast cells and eosinophils in the bronchial mucosa of symptomatic atopic asthmatics and healthy control subjects using immunohistochemistry. Am Rev Respir Dis 1990;142(4):863-871.

19. Bradley BL, Azzawi M, Jacobson M, Assoufi B, Collins JV, Irani $A M$, et al. Eosinophils, T-lymphocytes, mast cells, neutrophils, and macrophages in bronchial biopsy specimens from atopic subjects with asthma: comparison with biopsy specimens from atopic subjects without asthma and normal control subjects and relationship to bronchial hyperresponsiveness. J Allergy Clin Immunol 1991;88(4):661-674.

20. Kay AB. Asthma and inflammation. J Allergy Clin Immunol 1991;87(5):893-910.

21. Poston RN, Chanez P, Lacoste JY, Litchfield T, Lee TH, Bousquet J. Immunohistochemical characterization of the cellular infiltration in asthmatic bronchi. Am Rev Respir Dis 1992;145(4 Pt 1):918-921.

22. Saetta M, Di Stefano A, Maestrelli P, De Marzo N, Milani GF, Pivirotto $\mathrm{F}$, et al. Airway mucosal inflammation in occupational asthma induced by toluene diisocyanate. Am Rev Respir Dis 1992;145(1):160-168

23. Schwarze J, Cieslewicz G, Joetham A, Sun LK, Sun WN, Chang TW, et al. Antigen-specific immunoglobulin-A prevents in- creased airway responsiveness and lung eosinophilia after airway challenge in sensitized mice. Am J Respir Crit Care Med 1998;158(2):519-525.

24. Mapp CE, Lapa e Silva JR, Lucchini RE, Chitano P, Rado V, Saetta $\mathrm{M}$, et al. Inflammatory events in the blood and airways of guinea pigs immunized to toluene diisocyanate. Am J Respir Crit Care Med 1996;154(1):201-208.

25. Vercelli D, Jabara HH, Arai K, Yokota T, Geha RS. Endogenous interleukin 6 plays an obligatory role in interleukin 4-dependent human IgE synthesis. Eur J Immunol 1989;19(8):14191424.

26. Swain SL, Weinberg AD, English M, Huston G. IL-4 directs the development of Th2-like helper effectors. J Immunol 1990; 145(11):3796-3806.

27. Dearman RJ, Moussavi A, Kemeny DM, Kimber I. Contribution of CD4+ and CD8+ T lymphocyte subsets to the cytokine secretion patterns induced in mice during sensitization to contact and respiratory chemical allergens. Immunology 1996; 89(4):502-510.

28. Crimi E, Gaffi D, Frittoli E, Borgonovo B, Burastero SE. Depletion of circulating allergen-specific TH2 T lymphocytes after allergen exposure in asthma. J Allergy Clin Immunol 1997; 99(6 Pt 1):788-797.

29. Del Prete GF, De Carli M, D’Elios MM, Maestrelli P, Ricci M, Fabbri $\mathrm{L}$, et al. Allergen exposure induces the activation of allergen-specific Th2 cells in the airway mucosa of patients with allergic respiratory disorders. Eur J Immunol 1993;23(7):14451449.

30. Satoh T, Kramarik JA, Tollerud DJ, Karol MH. A murine model for assessing the respiratory hypersensitivity potential of chemical allergens. Toxicol Lett 1995;78(1):57-66.

31. Swierczynska-Machura D, Nowakowska-Swirta E, WalusiakSkorupa J, Piasecka-Zelga J, Swiercz R, Nocuń M, et al. Effect of inhaled toluene diisocyanate on local immune response based on murine model for occupational asthma. J Immunotoxicol 2013. doi:10.3109/1547691X.2013.818745.

32. Świerczyńska-Machura D, Walusiak-Skorupa J, NowakowskaŚwirta E, Piasecka-Zelga J, Świercz R, Pałczyński C. Immunological determinants in a murine model of toluene diisocyanate-induced asthma. Int J Occup Med Environ Health 2012; 25(4):492-498.

33. De Vooght V, Vanoirbeek JA, Luyts K, Haenen S, Nemery B, Hoet $\mathrm{PH}$. Choice of mouse strain influences the outcome in a mouse model of chemical-induced asthma. PLoS One 2010; 5(9):e12581. 
34. Fisseler-Eckhoff A, Bartsch H, Zinsky R, Schirren J. Environmental isocyanate-induced asthma: morphologic and pathogenetic aspects of an increasing occupational disease. Int J Environ Res Public Health 2011;8(9):3672-3687.

35. Lee C, Kolesnik TB, Caminschi I, Chakravorty A, Carter W, Alexander WS, et al. Suppressor of cytokine signalling 1 (SOCS1) is a physiological regulator of the asthma response. Clin Exp Allergy 2009;39(6):897-907.

36. Vanoirbeek JA, De Vooght V, Nemery B, Hoet PH. Multiple challenges in a mouse model of chemical-induced asthma lead to tolerance: ventilatory and inflammatory responses are blunted, immunologic humoral responses are not. Toxicology 2009;257(3):144-152.

37. Vanoirbeek JA, Tarkowski M, De Vooght V, Nemery B, Hoet PH. Immunological determinants in a mouse model of chemicalinduced asthma after multiple exposures. Scand J Immunol 2009;70(1):25-33. 